\title{
Methodological considerations in defining child maltreatment
}

\author{
Andreas Jud • Markus A. Landolt • Ulrich Lips
}

Received: 18 March 2010/Accepted: 18 March 2010/Published online: 10 April 2010

(C) Springer-Verlag 2010

Braillon, Bewley and Dubois [1] rightly stress the importance of the deleterious effects of secondhand smoke on children's physical health.

Uniform definitions of child maltreatment and neglect are lacking. However, definitions describing physical maltreatment as the intentional use of physical force against a child that results in or has the potential to result in physical injury are broadly accepted by child protection researchers and practitioners $[2,3]$. The behaviour grouped within this definition-like hitting, kicking, punching or beating-possibly shares comparable causes and consequences. This assumption is endorsed by the substantial research on risk factors of physical maltreatment [4].

Although we would restrain from defining secondhand smoke as physical maltreatment, regularly exposing a child to secondhand smoke can be defined as a failure to provide the basic need of a healthy environment. This failure often coincides with other neglectful behaviour like taking children out till late at night, deficits in nutrition or con-

A. Jud $(\bowtie) \cdot$ M. A. Landolt $\cdot$ U. Lips

University Children's Hospital Zürich,

Steinwiesstrasse 75 ,

8032 Zürich, Switzerland

e-mail: andreas.jud@kispi.uzh.ch sumption of alcohol during pregnancy. Such patterns are regularly referred to hospital child protection teams or other child protection agencies. Research on the epidemiology of child maltreatment identifies neglect as the most common form of maltreatment with enormous costs for public health $[3,5,6]$.

Conflicts of interest None

\section{References}

1. Braillon A, Bewley S, Dubois G. (2010) Secondhand smoke is the most frequent cause of child maltreatment. Eur J Pediatrics (in press)

2. Cicchetti D, Toth SL (2005) Child maltreatment. Ann Rev Clin Psychol 1:409-438

3. Leeb RT, Paulozzi L, Melanson C et al (2008) Child maltreatment surveillance: Uniform definitions for public health and recommended data elements, version 1.0. Atlanta (GA): Centers for Disease Control and Prevention, National Center for Injury Prevention and Control

4. Black DA, Heyman RE, Slep AMS (2001) Risk factors for child physical abuse. Aggress Violent Beh 6(2-3):121-188

5. Schumacher JA, Slep AMS, Heyman RE (2001) Risk factors for child neglect. Aggress Violent Beh 6(2-3):231-254

6. US Department of Health \& Human Services (2008) Child maltreatment 2006. US Government Printing Office, Washington 